\begin{tabular}{|c|c|}
\hline in & $\begin{array}{l}\text { International Journal of Trend in Scientific } \\
\text { Research and Development (IJTSRD) }\end{array}$ \\
\hline 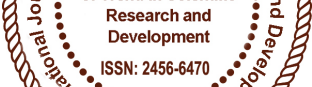 & International Open Access Journal \\
\hline 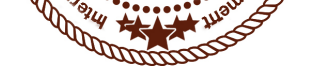 & ISSN No: 2456 - 6470 | www.ijtsrd.com | Volume - 2 | Issue - 5 \\
\hline
\end{tabular}

\title{
Automatic Light Intensity Monitoring using Modern Technology
}

\author{
Tsering Lasket ${ }^{1}$, Shavet Sharma ${ }^{2}$ \\ ${ }^{1}$ M.Tech Scholar, ${ }^{2}$ Assistant Professor \\ Department of Electrical Engineering, Sri Sai College of Engineering \& Technology \\ Badhani, Pathankot, Punjab, India
}

\section{ABSTRACT}

The electricity is a gift to mankind and needs proper management. As we all know we are very busy, and are unable to find time even to switch the lights wherever not necessary. The street lights will be switched on in the evening before the sun sets and they are switched off the next day morning after there is sufficient light on the roads. The paper focus on the applications of modern technology in energy saving.

\section{KEYWORD: Sensor, IOT, LED}

\section{INTRODUCTION}

Automatic Light Intensity Monitoring concept mainly aims at saving energy The thought of outlining a new framework for the street lights is due to the immense power consumption of the present lighting system that consume about world's 78\% of electricity. Smart street lightening system is a project on intelligent illumination control of street lights to optimize the problem of power consumption and illumination of the streets, late in the night. Street lights today are being replaced by LED street lighting system, which reduces the power consumption. The other advantage of LED is that the intensity can be controlled easily. Hence, movement detection based street light control can be designed easily. Street Light Control System which operates automatically is not only easiest but also the intelligent system. This system can be set to operate in automatic mode, which regulates the streetlight according to brightness and dimness Algorithm and Light intensity. This control can make a reasonable adjustment according to the seasonal variation. We can take the initiative to control streetlights through microcontrollers.

\section{Street Lightning}

The present time street lightning have got many problems. The hindrance of the present framework is that it requires manual operation of the road light which needs labor. In sunny and rainy days, ON and OFF time differ discernibly which is one of the significant hindrances of the present street lights systems. Conventional street lighting systems are on most of the day without purpose because these are operated manually and the consequence is that a large amount of power is wasted meaninglessly. With the wide accessibility of adaptable lighting innovation like light emitting diode (LED) lights and all over accessible remote web association, quick responding, dependable working, and power moderating street lighting frameworks get to be reality. The reason for this work is to showcase the Smart Street Lighting framework. The goal of this paper is to plan an automated lighting framework which focuses on the saving of power, to construct a vitally energy efficient smart lighting framework with integrated sensors and controllers, to outline a smart lighting system with particular methodology plan, which makes the system more user friendly and that requires less involvement of manpower.

\section{Monitoring}

Street lighting system monitoring and controlling is the essentially importance in developing country like India. There was a large amount of power is wasted, if we forgot to switch off the light means that will be glowing all the day. But the proposed system is a good power saver method, which are controlled by the sensors. This project contains various monitoring stations and one base station. The monitoring station consists of two sensors, Arduino microcontroller 
board, relay, Ethernet shield, NRF and so on. The monitoring station located in each lamp post, they have above mentioned parts. These devices are works together and transfer all of the sensed information to the microcontroller module. The PIR Sensor used to detect the presence of human/vehicle. Whenever they detect human presence it measures the intensity of light. For the intensity measures we are using this LDR sensor. A light sensor can measure the brightness of the sunlight and provides sensor information. In day time intensity of light will be high; because of negative temperature co-efficient so no need to have lighting system. When the intensity of light becomes low that time necessary of the street lighting. All these information will pass to the base station via NRF devices. From the base station a messages passing to the microcontroller to glow the street lights according to the intensity of light. And also movement based information send to the base station for corresponding action by the controller. The whole system work is based on the sensors presence. The main idea behind the system is that the LED light will be in off position at day time. Even at day time if the intensity of light is lower due to weather conditions like fog, thunderstorm etc. then the light will get turned on. When PIR sensor detects the vehicles, the brightness of the LED will be high. When there is no vehicle, brightness will be low. This is done, so as to minimize the power usage. Here turned on lights only when it is needed. At night sometimes roads will be empty and hence there is no use of illuminating all the lamps. So we can lower the intensity of LEDs and can conserve more power. It is sure, that we can't leave in a society without power. So we need to maximize the usage of renewable energy so that we can preserve conventional resources. Normal solar PV based street lighting system lacks automation. The problem is that it will be in on state even though there is no need of light and hence it causes loss of power. Yet another problem is power is wasted during late night when there is no movement on roads. In this paper a new technique is suggested to automate the entire system. Here, when there is no necessity of light the system will go into a power down mode and the lamps won't glow. Sensors used to sense the intensity of light and presence of humans or cars. By using that sensor value the lights get turned on/off automatically. At present, street lamps control at most of the urban is only by manual control, which is inefficient and a waste of manpower, change the resistance by using of light-sensitive device to control street lamps light up automatically in the evening after dark, turn off automatically after dawn in the morning, but the low reliability of the method, vulnerable to interference, night street lighting is too bright and are a waste of energy and other issues; 1) Time-control method (that is, from time to time opening and closing control). 2) This method achieved automatic control of street light, thereby reducing the labor intensity and lowering labor costs and improving the efficiency of street lighting control. Automation, Power consumption and Cost Effectiveness are the important considerations in the present field of electronics and electrical related technologies.

\section{Technology}

The IOT is rapidly becoming a reality that surrounds us and intersects with many aspects of our lives. Pervasive connectivity and advances in ICT technologies have made possible the connection of more and more devices to the Internet. This is leading to a new wave of applications that have the potential to dramatically improve the way people live, learn, work, and entertain themselves. Sensors play a key role in connecting the physical world (temperature, $\mathrm{CO}_{2}$, light, noise, moisture) with the digital world of IOT.

Sensors are sophisticated devices that are frequently used to detect and respond to electrical or optical signals. A Sensor converts the physical parameter (for example: temperature, blood pressure, humidity, speed, etc.) into a signal which can be measured electrically. Let's explain the example of temperature. The mercury in the glass thermometer expands and contracts the liquid to convert the measured temperature which can be read by a viewer on the calibrated glass tube.

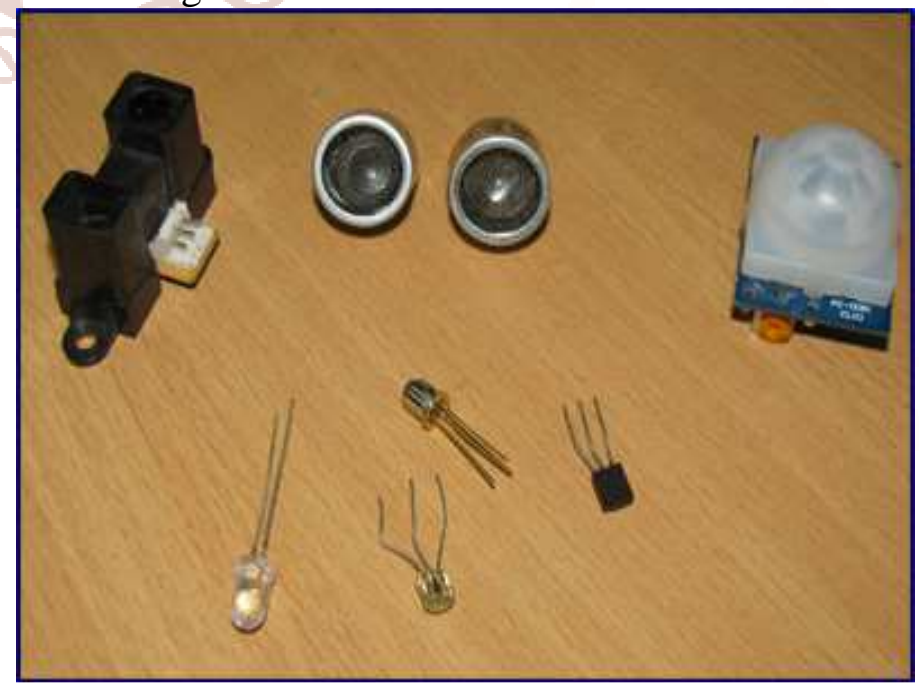

Different types of sensors 
Sensors are playing and will continue to play a key role in enabling innovative solutions. Smart technologies such as smart sensors, data acquisition systems, ubiquitous data connectivity, and big data analytics-provide key technology building blocks. Integrated appropriately, they provide efficiencies, scalability, and cost reduction. They also act as an innovation platform for long-term solutions to enable meaningful citizen engagement or "stickiness." The potential of these systems will continue to evolve, particularly as the trajectory and merging of technologies increases.

\section{Conclusion:}

In this paper I have briefly described technical aspects for electrical domain. The IOT is the very special technology used to control hardware devices using internet technology. The paper is about how to save energy using latest and emerging technologies like IOT, Cloud Platform, Microcontrollers etc.

\section{REFERENCES:}

1. Michele Magno, Tommaso Polonelli, Luca, and Emanuel Popovici, A Low Cost, Highly Scalable Wireless Sensor Network Solution to Achieve Smart LED Light Control for Green Buildings. IEEE Sensors Journal 15(5): 2963-2973 (2015).

2. P. Y. Chen, Y. H. Liu, Y. T. Yau and H C. Lee, Development of an energy efficient street light driving system, Proc. IEEE Int. Conf. Sustain. Energy Technol. Pp.761-764, Nov.24-27 (2008).

3. W. Yue, S. Changhong, Z. Xianghong, and Y. Wei, Design of new intelligent street light control system, Proc. 8th IEEE Int. Conf. Control Autom. Pp.1423-1427, Jun. 9-11 (2010).

4. Archana. G, Aishwarya. N, Anitha. J, Vijay Kumar, Intelligent Street Light System. International Journal of Recent Advances in Engineering and Technology 3: 16-18 (2015).

5. Fabio Leccese, Remote-Control System of High Efficiency and Intelligent Street Lighting Using a ZigBee Network of Devices and Sensors. IEEE Transactions on Power Delivery 28(1): 21-28 (2013).

6. Dipak A. Mhaske and S. S. Katariya, Smart Street Lighting using a ZigBee \& GSM Network for High Efficiency \& Reliability. International Journal of Engineering Research \& Technology (IJERT) 3(4): 175-179 (2014).
7. Sharath Patil G. S., Rudresh S. M., Kallendrachari, K. M., Kiran Kumar and Vani H. V., Design and Implementation of Automatic Street Light Control Using Sensors and Solar Panel. Int. Journal of Engineering Research and Applications 5(6): 79-100 (2015).

8. Gustavo W. Denardin, Carlos H. Barriquello, Alexandre Campos and Ricardo N. Do Pradoan, An Intelligent System for Street Lighting Monitoring and Control. IEEE Conference Paper Pp. 274-278 (2009).

9. Chunguo Jing, Dongmei Shu and Deying $\mathrm{Gu}$ Design, Design of Streetlight Monitoring and Control System Based on Wireless Sensor Networks. 2nd IEEE Conference on Industrial Electronics and Applications Pp. 62-57(2007).

10. Velaga, R. and Kumar, A. 2012. Technoeconomic evaluation of the feasibility of a smart street system: A case study of rural India. Procedia Social and Behavioral Sciences. 62, 1220-1224.

11. Bruno, A., Di Franco, F. and Rasconà, G. 2012. Smart street lighting. EE Times http://www.eetimes.com/design/smart-energydesign/4375167/Smart-street-lighting.

12. The e-JIKEI Network Promotion Institute, et al. Smart street light system with communication means. Published unexamined patent application in Japan P2011-165573A (in Japanese).

13. Smart street light system with energy... (PDF Download Available). Available from: https://www.researchgate.net/publication/2623529 65_Smart_street_light_system_with_energy_savin g_function_based_on_the_sensor_network [accessed Jun 20 2018].

14. Harshit Satyasee, Gaurav Sahu, Manisha Agarwal, Jagrity Priya "Light Intensity Monitoring \& Automation of Street Light Control by IoT" 2017, International Journal of Innovations \& Advancement in Computer Science, Volume 6, Issue 10 .

15. Gouthami. C, Santosh. C, A. Pavan Kumar, Karthik. A, Ramya. K. R "Design and Implementation of Automatic Street Light Control System using Light Dependent Resistor" 2016, International Journal of Engineering Trends and Technology, Volume 35 Number 10. 
International Journal of Trend in Scientific Research and Development (IJTSRD) ISSN: 2456-6470

16. K. SanthaSheela, S. Padmadevi "Survey on Street Lighting System Based On Vehicle Movements" 2014, International Journal of Innovative Research in Science, Engineering and Technology, Vol. 3, Issue 2.

17. Reza Mohamaddoust, Abolfazl Toroghi Haghighat, Mohamad Javad Motahari Sharif, Niccolo Capanni “ A Novel Design of an
Automatic Lighting Control System for a Wireless Sensor Network with Increased Sensor Lifetime and Reduced Sensor Numbers" 2011, Sensors, ISSN 1424-8220.

18. Ying-Wen Bai and Yi-Te $\mathrm{Ku}$ "Automatic Room Light Intensity Detection and Control Using a Microprocessor and Light Sensors" 2008, IEEE Xplore.

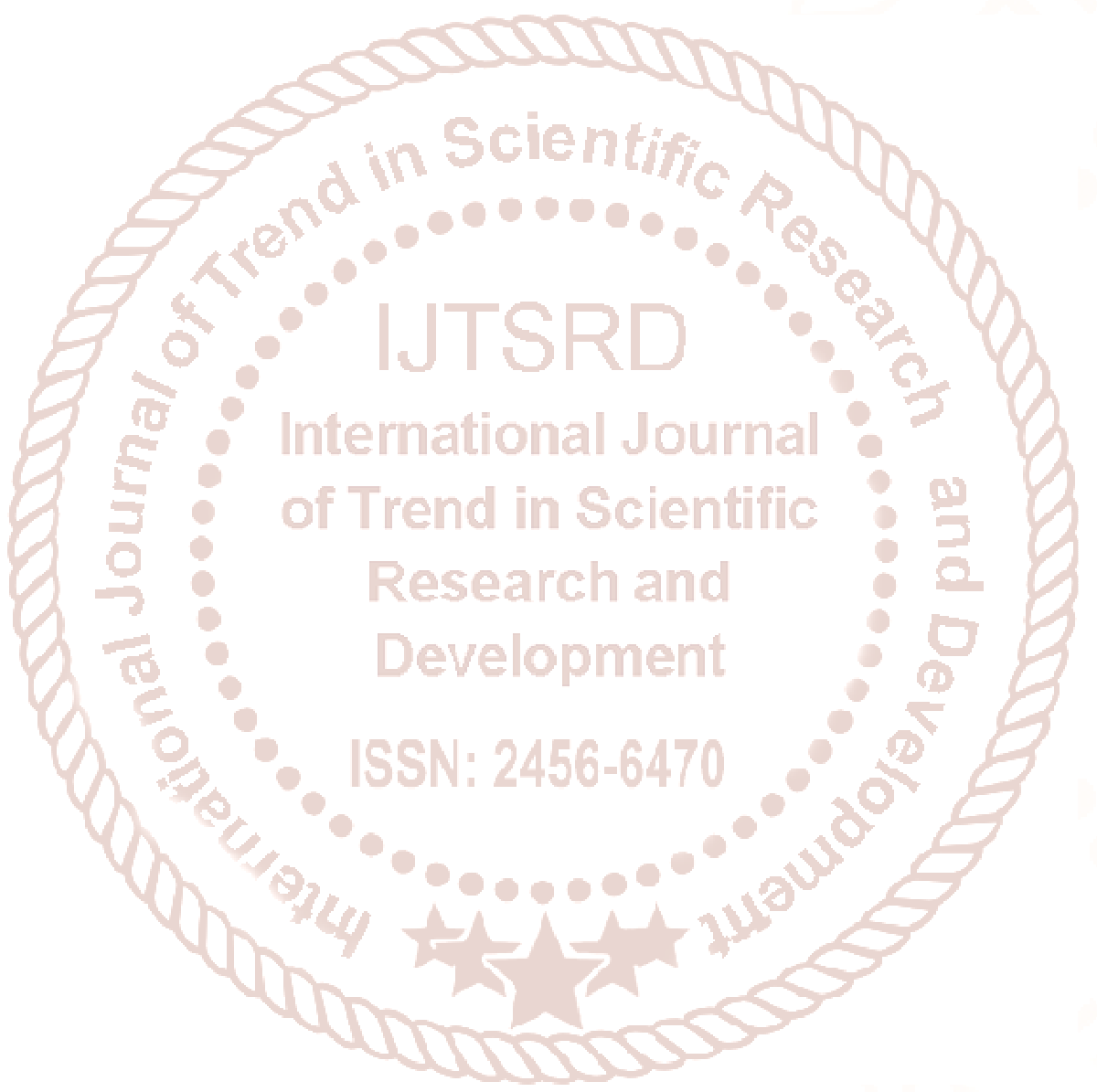

